\title{
A validated LC-MSMS method for the simultaneous quantification of meropenem and vaborbactam in human plasma and renal replacement therapy effluent and its application to a pharmacokinetic study
}

\author{
Suzanne L. Parker ${ }^{1} \cdot$ Saurabh Pandey $^{1} \cdot$ Fekade B. Sime $^{1,2} \cdot$ Jeffrey Lipman ${ }^{1,3} \cdot$ Jason A. Roberts ${ }^{1,2,3,4} \cdot$ Steven C. Wallis ${ }^{1}$
}

Received: 28 July 2019 / Revised: 12 September 2019 / Accepted: 1 October 2019 /Published online: 16 November 2019

(C) Springer-Verlag GmbH Germany, part of Springer Nature 2019

\begin{abstract}
A simple method for the simultaneous quantification of meropenem and the recently approved $\beta$-lactamase inhibitor, vaborbactam, in human plasma and renal replacement therapy effluent (RRTE) was developed and validated. This antibiotic combination protects a primary $\beta$-lactam, meropenem, with a new $\beta$-lactamase inhibitor, and expands the limited options for treatment of multidrug-resistant Gram-negative infections. Meropenem, vaborbactam, and the internal standards $\left[{ }^{2} \mathrm{H}_{6}\right]-$ meropenem and sulbactam in plasma and RRTE were processed using acetonitrile followed by a chromatographic separation on a Poroshell HPH-C18 column with a gradient elution of the mobile phases and monitored using mass spectrometry detection. The calibration range was 0.05 to $100 \mu \mathrm{g} \mathrm{mL}^{-1}$ for both meropenem and vaborbactam. The intra-day and inter-day precision and accuracy were less than $15 \%$ for both meropenem and vaborbactam and the recovery from plasma was $96 \%$ for both meropenem and vaborbactam and the recovery from RRTE was $93 \%$ and $103 \%$ for meropenem and vaborbactam, respectively. This methodology was successfully applied to an ex vivo characterisation study of the effects of renal replacement therapy modalities on the pharmacokinetics of meropenem and vaborbactam (Antimicrob Agents Chemother 62(10), 2018).
\end{abstract}

Keywords Meropenem $\cdot$ Vaborbactam $\cdot$ Chromatography $\cdot$ Mass spectrometry $\cdot$ Antibiotic

\section{Introduction}

The research and development of novel antibiotics to treat carbapenem-resistant Gram-negative bacteria have been identified by the World Health Organisation's (WHO) as being a critical priority [1]. Meropenem-vaborbactam is a combination

Suzanne L. Parker

suzanne.parker@uq.edu.au

1 UQ Centre for Clinical Research, The University of Queensland, Royal Brisbane \& Women's Hospital, Brisbane, QLD 4029, Australia

2 Centre for Translational Anti-Infective Pharmacodynamics, School of Pharmacy, The University of Queensland, Brisbane, QLD 4029, Australia

3 Department of Intensive Care Medicine, Royal Brisbane \& Women's Hospital, Brisbane, QLD 4029, Australia

4 Department of Pharmacy, Royal Brisbane \& Women's Hospital, Brisbane, QLD 4029, Australia carbapenem and $\beta$-lactamase inhibitor antibiotic approved by the US Food and Drug Administration in late 2017 for treatment of complicated urinary tract infections [2] and by the European Medicines Agency in 2018 for complicated urinary tract infections, complicated intra-abdominal infections, and for hospital-acquired pneumonia, including ventilator-associated pneumonia [3]. This antibiotic protects a primary $\beta$-lactam, meropenem, with a new $\beta$-lactamase inhibitor, and expands the limited options for treatment of multidrug-resistant Gramnegative infections [4]. It is available under the trade-name Vabomere ${ }^{\circledR}$, previously named Carbavance ${ }^{\circledR}$. It is not uncommon for patients with infections from carbapenemase-resistant pathogens to develop severe renal impairment that necessitates the use of renal replacement therapy [5, 6]. There is accumulating evidence that this medical intervention can necessitate dosing adjustment of antibiotics due to altered and variable extracorporeal clearances [6-8]. As neither meropenem nor vaborbactam is metabolized, with both primarily excreted unchanged in the urine [9], no methods for the analysis of metabolites are required. 
Methodology to quantify drugs in biological fluids is important to support pre-clinical and clinical studies. Chromatographic methods have been reported for meropenem in plasma [10-23] and serum [24-27] using UV [12, 16, 26], diode array $[15,20,28,29]$, and mass spectrometry $[10,11$, $13,14,17-19,21-25,27,30]$ detection. To the best of our knowledge, there are currently no analytical methods reporting the quantification of the combination of meropenem-vaborbactam in biological fluids and no methods for the quantification of newly developed $\beta$-lactamase inhibitor, vaborbactam.

We have developed a method suitable for the reliable and sensitive quantification of meropenem and vaborbactam in human plasma and renal replacement therapy fluid effluent (RRTE) using LC-MSMS. The advantages of this method include a small sample volume $(10 \mu \mathrm{L})$ with a simple protein precipitation sample treatment. This methodology has been applied to an ex vivo characterisation study of the effects of renal replacement therapy modalities on the pharmacokinetics of meropenem and vaborbactam [6].

\section{Experimental}

\section{Materials}

Meropenem and vaborbactam were supplied as a pharmaceutical combination product (Carbavance ${ }^{\circledR}$ ) by Rempex Pharmaceuticals (San Diego, USA) containing $1 \mathrm{~g}$ of meropenem and $1 \mathrm{~g}$ of vaborbactam, $\left[{ }^{2} \mathrm{H}_{6}\right]$-meropenem was supplied by AlsaChim (Illkirch, France) and sulbactam was supplied by Sigma-Aldrich (St Louis, USA). The chemical structures for these compounds are found in Fig. 1. Acetonitrile was HPLC-gradient grade (Merck, Darmstadt, Germany) and formic acid (Fisher Scientific, Victoria, Australia) was analytical grade. Ultrapure water was obtained using a Permutit system (resistivity at $25{ }^{\circ} \mathrm{C}$ greater than 18 $\Omega \mathrm{Mcm}$ ). Drug-free human plasma was obtained from Innovative Research (Michigan, USA). Compound sodium lactate IV solution was obtained from Baxter (Old Toongabbie, Australia). For drug-free RRTE, ultrafiltered drug-free plasma was combined with compound sodium lactate solution $(10 / 90 \% \mathrm{v} / \mathrm{v})$.

\section{Chromatographic conditions}

A Shimadzu 8030+ triple quadrupole mass spectrometer (MS) detector was used in this analysis. An electro-spray ionisation (ESI) source interface, switching between both positive ion (for meropenem and $\left[{ }^{2} \mathrm{H}_{6}\right]$-meropenem) and negative ion mode (for vaborbactam and sulbactam), was used for the selected reaction monitoring (SRM) LC-MSMS analysis. Nitrogen was used as the nebulizing gas, with interface setting consisting of the nebulizing gas flow of $3 \mathrm{~L} \mathrm{~min}^{-1}$, a desolvation line temperature of $250^{\circ} \mathrm{C}$, heat block temperature $400{ }^{\circ} \mathrm{C}$, and a drying gas flow of $10 \mathrm{~L} \mathrm{~min}^{-1}$. The collision gas was argon. Meropenem and $\left[{ }^{2} \mathrm{H}_{6}\right]$-meropenem were monitored in positive mode electrospray. Vaborbactam and sulbactam were monitored by negative mode electrospray. MS conditions for meropenem, $\left[{ }^{2} \mathrm{H}_{6}\right]$-meropenem, vaborbactam, and sulbactam are reported in Table 1.

The liquid chromatographic analysis was performed using a Shimadzu Nexera2 LC equipped with dual pumps and an autosampler compartment set to $5^{\circ} \mathrm{C}$. The analytical column was a Poroshell HPH-C18 $2.1 \times 50 \mathrm{~mm}, 2.7 \mu \mathrm{m}$ column (Agilent, USA) operated at room temperature. Mobile phase A was $0.1 \%$ formic acid in water $(\mathrm{v} / \mathrm{v})$, and mobile phase $\mathrm{B}$ was $100 \%$ acetonitrile with $0.1 \%$ formic acid $(\mathrm{v} / \mathrm{v})$. The mobile phase $\mathrm{B}$ was delivered with gradient from 5 to $50 \%$ at a flow rate of $0.4 \mathrm{~mL} \mathrm{~min}^{-1}$ for $5.5 \mathrm{~min}$ run-time and produced a back pressure of approximately $3300 \mathrm{psi}$.

\section{Preparation of the calibration standards and quality control samples}

Meropenem-vaborbactam is co-formulated to contain equal amounts of meropenem and vaborbactam. Aqueous standards were prepared from the co-formulated standard with a concentration of 50,100, and $1000 \mathrm{mg} \mathrm{mL}^{-1}$ for meropenem and vaborbactam. $\left[{ }^{2} \mathrm{H}_{6}\right]$-meropenem and sulbactam were used as internal standards. $\left[{ }^{2} \mathrm{H}_{6}\right]$-meropenem was prepared to contain $100 \mu \mathrm{g} \mathrm{mL}^{-1}$ in water and sulbactam was prepared to contain $1550 \mu \mathrm{g} \mathrm{mL}^{-1}$ in water. These internal standard stock solutions were combined to prepare a working solution containing $2 \mu \mathrm{g} \mathrm{mL} L^{-1}$ of $\left[{ }^{2} \mathrm{H}_{6}\right]$-meropenem and $50 \mu \mathrm{g} \mathrm{mL}^{-1}$ of sulbactam. All aqueous stock solutions were stored at or below $-20^{\circ} \mathrm{C}$.

On the day of assay, calibration standards were prepared by serial dilution with water to contain both meropenem and vaborbactam in concentrations ranging from 0.05 to $100 \mu \mathrm{g} \mathrm{mL}^{-1}$. Each calibration range contained eleven (11) calibration standards at nominal concentrations of $0.05,0.1$, $0.2,0.5,1,2,5,10,20,50$, and $100 \mu \mathrm{g} \mathrm{mL}^{-1}$. Calibration standard solutions were prepared by combining these solutions with an equal volume of drug-free matrix (plasma or RRTE). The calibration standards were processed alongside the study and quality control samples.

Quality control samples were prepared from an aqueous stock solutions prepared to contain 100, 500, and $2000 \mathrm{mg} \mathrm{mL}^{-1}$ of meropenem and vaborbactam and stored at $-80^{\circ} \mathrm{C}$. Stock solutions were diluted with drug-free matrix (plasma or RRTE). Quality control samples were prepared to contain both meropenem and vaborbactam at concentrations of $0.3,1.5,10$, and $80 \mu \mathrm{g} \mathrm{mL}^{-1}$, with the dilution of drug-free matrix by aqueous stock maintained below $5 \%$. Quality control samples were stored at $-80{ }^{\circ} \mathrm{C}$ alongside the study samples. 
Fig. 1 Structures of meropenem (a), $\left[{ }^{2} \mathrm{H}_{6}\right]$-meropenem (b), vaborbactam $(\mathbf{c})$, and sulbactam $(\mathbf{d})$<smiles>C[C@@H](O)[C@H]1C(=O)N2C(C(=O)O)=C(S[C@@H]3CN[C@H](C(=O)N(C)C)C3)[C@H](C)[C@H]12</smiles><smiles>COB1O[C@@H](CC(=O)O)CC[C@@H]1NC(=O)Cc1cccs1</smiles>

b<smiles>C[C@H](O)[C@H]1C(=O)N2C(C(=O)O)=C(S[C@@H]3CN[C@H](C(=O)N(C)C)C3)[C@H](C)[C@H]12</smiles>

d<smiles></smiles>

\section{Sample preparation for analysis}

An aliquot $(10 \mu \mathrm{L})$ of study sample (plasma or RRTE) was combined with $10 \mu \mathrm{L}$ of water (to correspond to the dilution during preparation of the calibration standards). All samples were briefly vortexed followed by the addition of $10 \mu \mathrm{L}$ of the internal standard working solution (containing $2 \mu \mathrm{g} \mathrm{mL}^{-1}$ of $\left[{ }^{2} \mathrm{H}_{6}\right]$-meropenem and $50 \mu \mathrm{g} \mathrm{mL} \mathrm{L}^{-1}$ of sulbactam), except for a drug-free matrix sample which received $10 \mu \mathrm{L}$ of water. Samples were again vortexed briefly and $40 \mu \mathrm{L}$ of acetonitrile was added to all samples. Samples were vortexed for $3 \mathrm{~s}$ and then centrifuged for $5 \mathrm{~min}$ at $4000 \mathrm{~g}$ to remove precipitated proteins. The resulting supernatant was injected into the LCMSMS (sample injection volume of $0.2 \mu \mathrm{L}$ ).

\section{Data analysis}

For both meropenem and vaborbactam, the concentration of each study sample and quality control sample was obtained using data from the calibration line prepared from calibration standards within each batch. A quadratic regression based on peak area ratio (analyte/internal standard peak area response) against concentration ( $\mathrm{x}$ ) with a $1 / \mathrm{x}^{2}$ weighting was used for the mathematical basis of calibration line calculations.

\section{Method validation}

The bioanalytical method validation was performed with reference to the guidelines provided by the US FDA [31] and
Table 1 Mass spectrometry settings

\begin{tabular}{lllll}
\hline Analyte & Meropenem $^{\mathrm{a}}$ & Vaborbactam $^{\mathrm{b}}$ & {$\left[{ }^{2} \mathrm{H}_{6}\right]$-meropenem $^{\mathrm{a}}$} & Sulbactam $^{\mathrm{b}}$ \\
\hline Precursor ion & 384 & 296 & 390 & 232 \\
Product ion 1 (quantifying ion) & 68 & 234 & 147 & 140 \\
Product ion 2 (qualifier ion) & 141 & 278 & $\mathrm{NA}$ & $\mathrm{NA}$ \\
Dwell time (ms) & 100 & 100 & 100 & 100 \\
Q1 (V) & -19 & 14 & -15 & 25 \\
CE (V) & -45 & 21 & -20 & 14 \\
Q3 (V) & -27 & 24 & -15 & 24 \\
\hline
\end{tabular}

${ }^{\mathrm{a}}$ Precursor and product ions measured as [MH+]

${ }^{\mathrm{b}}$ Precursor and products ion measured as $\left[\mathrm{MH}^{-}\right]$ 
EMA [32]. The validation was assessed for limit of detection (LOD), lower limit of quantification (LLOQ), linearity, interand intra-day precision and accuracy, selectivity, recovery, matrix effects, and stability.

\section{Linearity, LOD, LLOQ, accuracy, and precision}

Linearity was assessed using data from calibration curves on six occasions across a calibration range of 0.05 to $100 \mu \mathrm{g} \mathrm{mL}^{-1}$ for both meropenem and vaborbactam in plasma, with the LLOQ tested at $0.05 \mu \mathrm{g} \mathrm{mL}^{-1}(n=5)$ with a pre-established acceptance criteria of $\pm 20 \%$ precision and accuracy. The LOD was defined as being the lowest peak distinguishable from the background noise, and calculated as greater than three-times the noise of the blank matrix sample. An assessment of accuracy and precision was performed from data obtained from the analysis of quality control samples at all four concentrations for meropenem and vaborbactam, which were assayed alongside freshly prepared calibration lines. Accuracy (percent relative error, \%RE) and precision (percent coefficient of variation, \%CV) was calculated against nominal quality control sample concentrations with a pre-established acceptance criteria of $\pm 15 \%$ precision and accuracy.

\section{Recovery, matrix effects, and selectivity}

Three different sets of samples were prepared: one prepared in drug-free matrix spiked before extraction (set A), one prepared in drug-free matrix and spiked after extraction (set $\mathrm{B}$ ), and one prepared in water ( $\operatorname{set} \mathrm{C}$ ). The extraction recovery was determined by the responses of set A relative to set $\mathrm{B}$. The matrix effects were calculated as described by Matsuzewski [33] by comparing the results of set $\mathrm{B}$ to set $\mathrm{C}$ with a preestablished acceptance criteria of $\pm 15 \%$ precision.

Selectivity testing was assessed to determine the influence of the presence of components of plasma and RRTE on the quantification of meropenem and vaborbactam. This was evaluated by testing different sources of drug-free plasma that contained different types of anticoagulant (including lithium heparin, ethylenediaminetetraacetic acid, and sodium citrate). Testing was performed by spiking drug-free matrix at the lower limit of quantification and calculating the precision of the resulting concentrations with a pre-established acceptance criteria of $\pm 15 \%$ precision and accuracy.

\section{Stability studies}

The stability of meropenem and vaborbactam was assessed in frozen storage $\left(-80^{\circ} \mathrm{C}\right)$ and across three freeze-thaw cycles (from $-80{ }^{\circ} \mathrm{C}$ to ambient temperature). This testing was performed using quality control samples prepared at four concentrations and comparing the results to nominal concentrations with a pre-established acceptance criteria of $\pm 15 \%$ precision and accuracy. Stability of aqueous stock solutions stored at $20{ }^{\circ} \mathrm{C}$ was assessed by comparing the area of meropenem and vaborbactam in stored solutions to those obtained in freshly prepared solutions with a pre-established acceptance criteria of $\pm 5 \%$ accuracy.

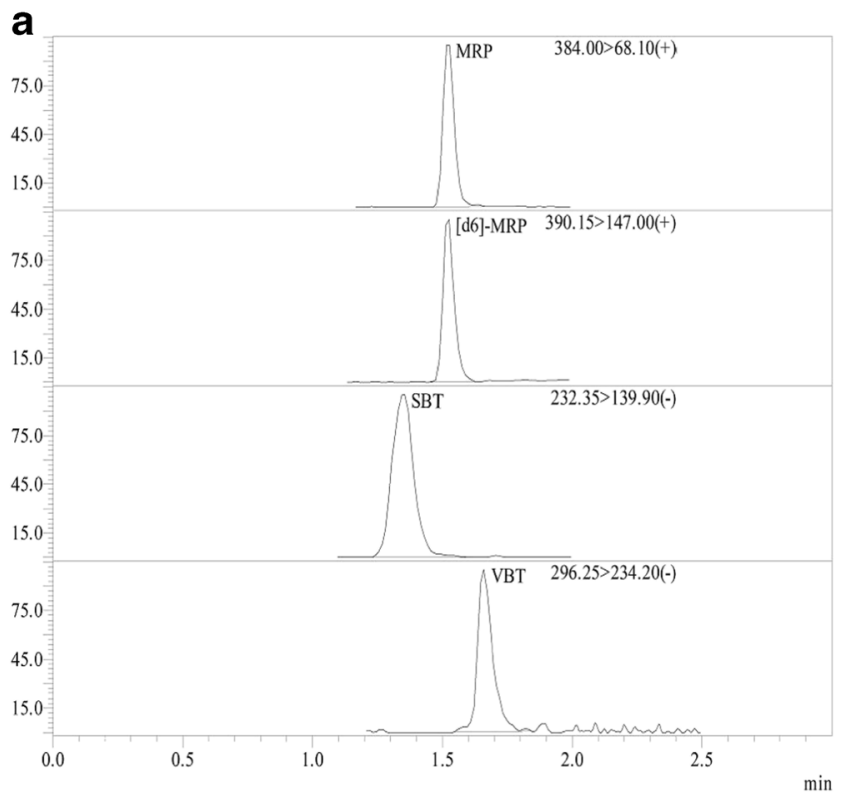

b

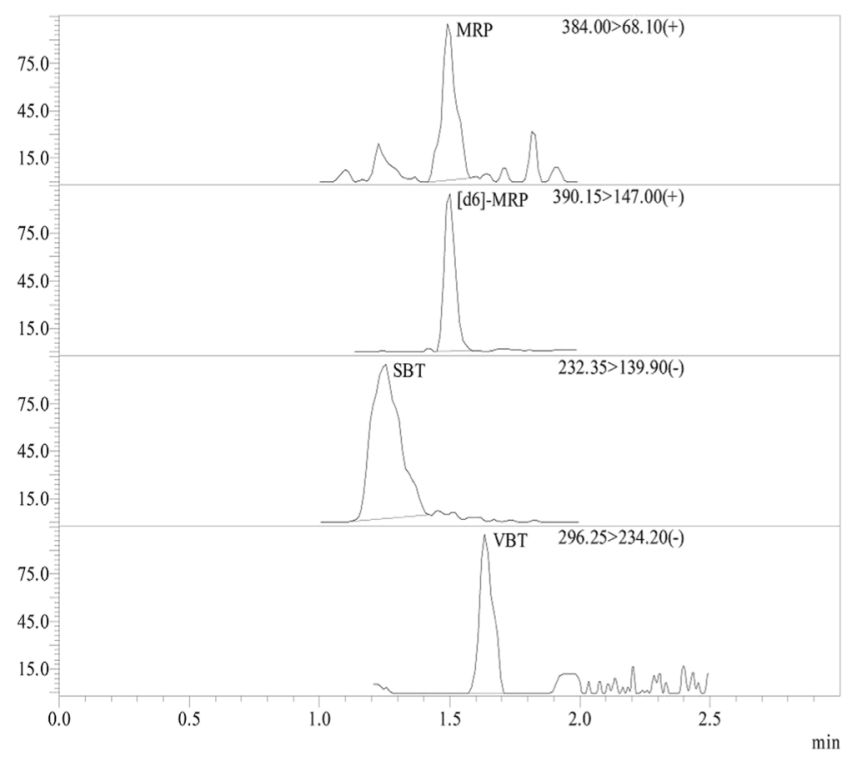

Fig. 2 LC-MSMS chromatograms for meropenem (MRP) and vaborbactam (VBT) at the lower limit of quantification $\left(0.05 \mu \mathrm{g} \mathrm{mL}^{-1}\right)$ and internal standards $\left[{ }^{2} \mathrm{H}_{6}\right]$-meropenem (d6-MRP) and sulbactam (SBT) at the working concentrations in plasma (a) and renal replacement therapy effluent (b) 

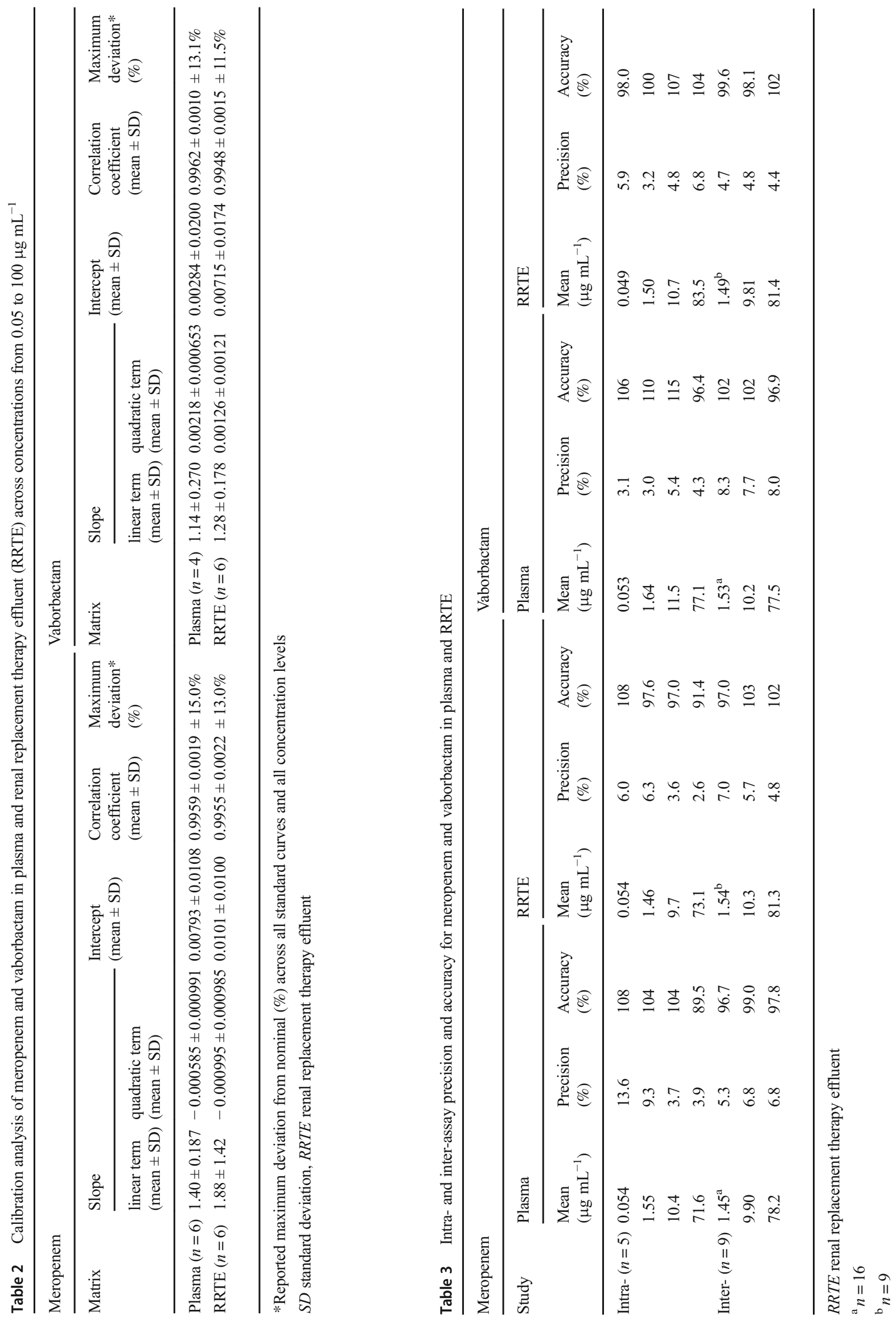
Table 4 Matrix effect and recovery studies for meropenem and vaborbactam

\begin{tabular}{|c|c|c|c|c|c|c|c|c|c|}
\hline \multirow{2}{*}{\multicolumn{2}{|c|}{$\frac{\text { Analyte }}{\text { Matrix }}$}} & \multicolumn{4}{|c|}{ Meropenem } & \multicolumn{4}{|c|}{ Vaborbactam } \\
\hline & & \multicolumn{2}{|c|}{ Plasma } & \multicolumn{2}{|l|}{ RRTE } & \multicolumn{2}{|c|}{ Plasma } & \multicolumn{2}{|l|}{ RRTE } \\
\hline Study & $\begin{array}{l}\text { Nominal concentration } \\
\left(\mu \mathrm{g} \mathrm{mL} L^{-1}\right)\end{array}$ & Mean & Precision $(\%)$ & Mean & Precision (\%) & Mean & Precision $(\%)$ & Mean & Precision $(\%)$ \\
\hline \multirow{3}{*}{$\begin{array}{l}\text { Matrix factor }\left(\mathrm{MF}_{\text {normalised }}\right) \\
(n=6)\end{array}$} & 20 & 1.07 & 7.4 & 1.08 & 11.2 & 1.01 & 3.2 & 1.01 & 5.6 \\
\hline & 50 & 1.08 & 8.1 & 0.95 & 12.7 & 1.00 & 7.2 & 1.02 & 4.8 \\
\hline & 100 & 1.08 & 12.9 & 1.08 & 8.3 & 1.04 & 3.3 & 1.03 & 3.4 \\
\hline \multirow[t]{3}{*}{ Recovery $(\%)(n=3)$} & 1.5 & 105 & 3.0 & 86.7 & 3.1 & 87.4 & 6.3 & 107 & 7.7 \\
\hline & 10 & 92.4 & 9.3 & 110 & 9.0 & 90.4 & 12.1 & 103 & 6.5 \\
\hline & 80 & 90.1 & 1.9 & 81.6 & 12.9 & 116.3 & 6.9 & 98.0 & 3.5 \\
\hline
\end{tabular}

$R R T E$ renal replacement therapy effluent

\section{Ex vivo study of the effects of renal replacement therapy modalities}

This methodology has been applied to the analysis of plasma and RRTE samples from an ex vivo study investigating the effects of renal replacement therapy modalities on the pharmacokinetics of meropenem and vaborbactam [6]. In this study, two concentrations of meropenem and vaborbactam ( 5 and $50 \mu \mathrm{g} \mathrm{mL}^{-1}$ ) were combined with drug-free human whole blood (maximum dilution of blood with aqueous standard was $0.1 \%$ ). Whole blood was circulated through a Prismaflex CRRT System (Gambro Lundia, Sweden) and renal replacement fluid introduced into the circuit by pre- or post-filter dilution. Serial blood samples $(1 \mathrm{~mL})$ were collected at $30,60,120$, and $180 \mathrm{~min}$. A sample of RRTE was removed from the effluent sampling port $(1 \mathrm{~mL})$. Blood samples were centrifuged $(5 \mathrm{~min}$ at $2000 \mathrm{~g}$ ) and both the resultant plasma and effluent samples were stored (within $15 \mathrm{~min}$ of collection) at $-80^{\circ} \mathrm{C}$ until assay.

\section{Results and discussion}

\section{Mass spectrometry}

This method employs rapid ionisation switching between positive and negative modes to allow simultaneous monitoring of all analytes. Fragmentation patterns were manually selected with subsequent auto-optimization using pre-programmed routines to identify alternative-fragmentation patterns and to optimise voltages. The protonated meropenem fragmentation pattern is due to the cleavage of the C-S bond to yield the ion at 141 and losses of hydrogen cyanide ( $\mathrm{HCN})$, but-3-enenitrile $(\mathrm{CHN})$ and $\mathrm{CO}$ to yield the ion at 68 [34]. There are no reports describing the fragmentation pattern of vaborbactam. The fragmentation observed in this study to form an ion at 234 may be due to an $\alpha$-cleavage for the loss of the carboxylic acid and the formation of an ion at 278 may be due to the loss of a hydroxyl ion. The stable labelled internal standard, $\left[{ }^{2} \mathrm{H}_{6}\right]-$ meropenem, was selected as an internal standard for the analysis of meropenem. Sulbactam was selected as an internal standard for vaborbactam due to its structural similarity and

Table 5 Stability studies for meropenem and vaborbactam in plasma

\begin{tabular}{|c|c|c|c|c|c|c|c|}
\hline \multirow[t]{2}{*}{ Stability study } & \multirow{2}{*}{$\begin{array}{l}\text { Nominal concentration } \\
\left(\mu \mathrm{g} \mathrm{mL} L^{-1}\right)\end{array}$} & \multicolumn{3}{|l|}{ Meropenem } & \multicolumn{3}{|l|}{ Vaborbactam } \\
\hline & & Mean $\left(\mu \mathrm{g} \mathrm{mL}^{-1}\right)$ & Accuracy $(\%)$ & Precision (\%) & Mean $\left(\mu \mathrm{g} \mathrm{mL}^{-1}\right)$ & Accuracy (\%) & Precision (\%) \\
\hline \multirow[t]{4}{*}{ Freeze-thaw $^{\mathrm{a}}(n=3)$} & 0.3 & 0.292 & 97.2 & 3.5 & 0.319 & 106 & 12.3 \\
\hline & 1.5 & 1.56 & 104 & 10.3 & 1.26 & 84.0 & 8.9 \\
\hline & 10 & 9.85 & 98.5 & 4.3 & 9.04 & 90.4 & 2.7 \\
\hline & 80 & 69.5 & 86.9 & 3.2 & 62.2 & 96.3 & 3.8 \\
\hline \multirow[t]{3}{*}{ Long term ${ }^{\mathrm{b}}(n=3)$} & 1.5 & 1.45 & 96.6 & 5.2 & 1.33 & 88.3 & 1.7 \\
\hline & 10 & 10.2 & 102 & 0.9 & 8.88 & 88.8 & 4.6 \\
\hline & 80 & 76.0 & 94.9 & 9.2 & 82.8 & 96.5 & 4.8 \\
\hline
\end{tabular}

${ }^{\mathrm{a}}$ Three freeze-thaw cycles

${ }^{\mathrm{b}}$ Stored at $-80^{\circ} \mathrm{C}$ for 2 months 
Fig. 3 Mean plasma concentrations $\left(\mu \mathrm{g} \mathrm{mL}^{-1}\right)$ of meropenem (a) and vaborbactam (b) from an ex vivo study of the extent of adsorption of meropenem and vaborbactam (using plasma concentrations of $5 \mu \mathrm{g} \mathrm{mL}^{-1}$ (triangle) and $50 \mu \mathrm{g} \mathrm{mL}^{-1}$ (circle)) on a renal replacement therapy circuit. Errors bars represent the standard deviation
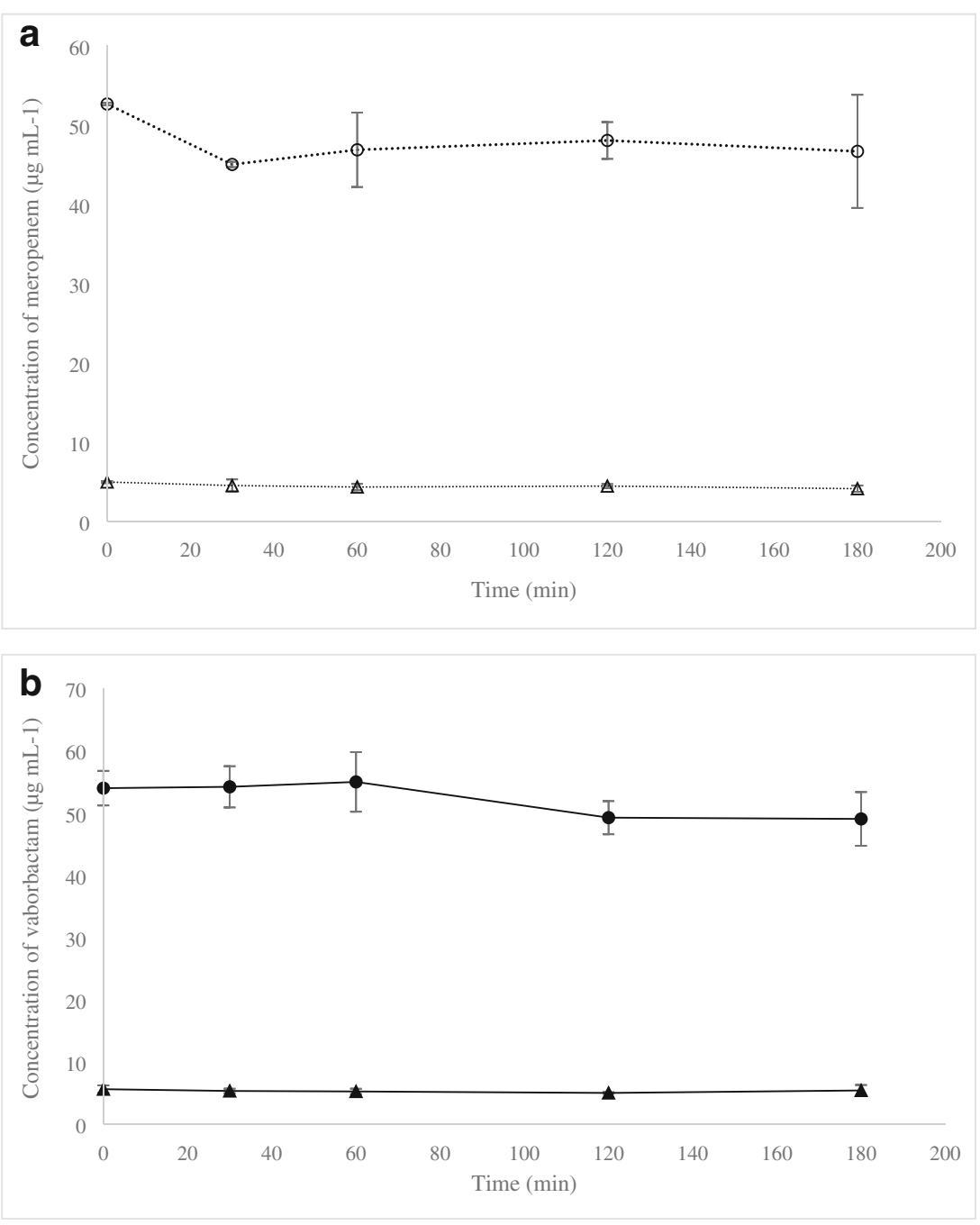

its similar behaviour during sample preparation and analysis [35], which compensated for variation in extraction efficiency and ionisation effects observed for vaborbactam. The identification of analyte peaks were confirmed using ion ratios calculated using the quantifying and qualifier ions (see Table 1), set at $95 \%$ for meropenem and $45 \%$ for vaborbactam, with the criteria for acceptance that all ion ratios fall within $\pm 20 \%$.

\section{Chromatography}

LC-MSMS chromatograms of samples extracted from plasma and RRTE at the LLOQ are shown in Fig. 2. The methodology was found to be suitable for both the proteaceous plasma and high salt concentration of RRTE. The retention time of meropenem and $\left[{ }^{2} \mathrm{H}_{6}\right]$-meropenem was $1.6 \mathrm{~min}$, vaborbactam eluted at $1.7 \mathrm{~min}$, and sulbactam at $1.3 \mathrm{~min}$. The total run time for each sample was $5.5 \mathrm{~min}$, allowing time for the column to reequilibrate from the cycle of the mobile phase gradient. A needlewash of $0.1 \%$ formic acid was used and no autosampler carryover was observed during the validation or study batch analysis.
This was confirmed by using a run-order in which after each injection of a calibration standard of $100 \mu \mathrm{g} \mathrm{mL}$, a drug-free and internal standard-free extracted matrix sample was injected.

\section{Validation}

The method was assessed across the validation concentration range of 0.05 to $100 \mu \mathrm{g} \mathrm{mL} \mathrm{m}^{-1}$ for both meropenem and vaborbactam in plasma and from 0.05 to $100 \mu \mathrm{g} \mathrm{mL}^{-1}$ for both meropenem and vaborbactam in RRTE. The concentration ranges selected for meropenem and vaborbactam were based on data from published clinical studies [7, 9, 36-38]. A quadratic regression with a $1 /$ concentration $^{2}$ weighting best described the response across the calibration range. The slope (linear and quadratic terms), intercept, mean correlation coefficient $\left(r^{2}\right)$, and percent maximum deviation from the nominal concentration for the calibration standards were calculated from testing performed on different occasions for both meropenem and vaborbactam and the results (mean \pm standard deviation) are reported in Table 2. The limit of detection for 
meropenem in both plasma and RRTE was $0.01 \mu \mathrm{g} \mathrm{mL}^{-1}$, respectively, and for vaborbactam in both plasma and RRTE was $0.02 \mu \mathrm{g} \mathrm{mL}^{-1}$, respectively. Precision and accuracy was assessed on one occasion as an intra-assay assessment $(n=5$; performed by one analyst on one instrument) and on eight occasions for plasma and on four occasions for RRTE as an inter-day assay assessment ( $n=16$ for plasma, $n=9$ for RRTE; performed by one analyst on one instrument). The results are reported in Table 3, with all results meeting acceptance criteria. The lower limit of quantification results met acceptance criteria for meropenem and vaborbactam in both matrices (Table 3).

The matrix factor study found there was no unacceptable enhancement or suppression signal response for plasma or RRTE. The results are reported in Table 4. The mean recovery across the three concentrations tested for the protein precipitation of plasma was $95.7 \pm 7.7 \%$ for meropenem and $95.7 \pm 7.0 \%$ for vaborbactam. The mean recovery across the three concentrations tested for the processing of RRTE was $92.9 \pm 15.3 \%$ for meropenem and $102.6 \pm 4.4 \%$ for vaborbactam. Recovery results for both analytes and at each concentration for plasma and RRTE are reported in Table 4.

The results of the selectivity testing found that when introducing variability in terms of different sources of plasma and types of anticoagulant at the LLOQ, the method was able to achieve an accuracy of $110 \%$ and $113 \%$ and precision of $8.5 \%$ and $14.8 \%$ for meropenem in plasma and RRTE, respectively. At the LLOQ, the method was able to achieve an accuracy of $94.8 \%$ and $98.9 \%$ and precision of $7.7 \%$ and $11.7 \%$ for vaborbactam in plasma and RRTE, respectively. Furthermore, there was no evidence of interference from the matrix, on the basis of there being no observable matrix enhancement or suppression or observable peak at the retention time of the peaks of interest.

Stability testing performed for three freeze-thaw cycles and long-term storage of 2 months found both meropenem and vaborbactam in plasma were stable in these conditions. The results are reported in Table 5. Stock solutions tested after storage of 1.5 months at $-80{ }^{\circ} \mathrm{C}$ showed acceptable deviations from freshly prepared solutions of $-0.2 \%$ for meropenem and $+4.4 \%$ for vaborbactam. Storage of processed samples on an autosampler at $4{ }^{\circ} \mathrm{C}$ for 1 day found acceptable deviation of $-7.6 \%$ for meropenem and $3.3 \%$ for vaborbactam, thus allowing re-injection of samples if an instrumental failure was to occur.

\section{Application to an ex vivo study of renal replacement therapy modalities}

This methodology has been successfully applied to an ex vivo study investigating the effect of renal replacement therapy on the pharmacokinetics of meropenem and vaborbactam [6]. Mean plasma concentrations of meropenem and vaborbactam collected over $3 \mathrm{~h}$ with a blood flow rate of $200 \mathrm{~mL} \mathrm{~min}{ }^{-1}$ circulated through a Prismaflex CRRT System are presented in Fig. $3(n=3)$. Renal replacement therapy effluent concentrations, with two blood flow rates (100 or $200 \mathrm{~mL} \mathrm{~min}{ }^{-1}$ ), across a range of filtration flow rates ( 1 to $4 \mathrm{~mL} \mathrm{~min}^{-1}$ ) and tested pre- and post-dilution, were measured ranging from 0.053 to $33.4 \mu \mathrm{g} \mathrm{mL} \mathrm{m}^{-1}$ for meropenem and 0.052 to $35.6 \mu \mathrm{g} \mathrm{mL}^{-1}$ of vaborbactam. Quality control samples tested within batches of study samples were prepared at $0.3,1.5,10$, and $80 \mu \mathrm{g} \mathrm{mL} \mathrm{m}^{-1}$ of meropenem and vaborbactam and the results for all quality control samples were within $13.6 \%$ precision and -93.5 to $106 \%$ accuracy.

\section{Conclusion}

A simple and reliable method for the simultaneous quantification of meropenem and vaborbactam in human plasma and renal replacement therapy fluid effluent (RRTE) was developed and validated. The method used a small sample volume $(10 \mu \mathrm{L})$ and employed a single-step extraction followed by chromatographic separation and mass spectrometry detection. This methodology has been applied to an ex vivo characterisation study of the effects of renal replacement therapy modalities on the pharmacokinetics of meropenem and vaborbactam [6]. The method is also suitable for a clinical pharmacokinetic study of co-administered meropenem and vaborbactam in humans.

Authors' contributions and authorship S. L. Parker: method design, data analysis, interpretation of results, and writing of manuscript; S. Pandey: method design, data analysis, interpretation of results, and writing of manuscript; F. B. Sime: ex vivo study protocol design and writing of manuscript; J. A. Roberts: interpretation of results and writing of manuscript; S. C. Wallis: method design, data interpretation, and writing of manuscript.

Funding information This study was funded by an investigator-initiated grant from Melinta Therapeutics, USA. SLP is a recipient of a National Health and Medical Research Council-funded Fellowship (APP1142757) and JAR is a recipient of a National Health and Medical Research Council-funded Centre for Research Excellence Research Excellence in Redefining Antimicrobial Use to Reduce Resistance (APP1044941, 1062040) and Fellowship (APP1048652).

\section{Compliance with ethical standards}

The study was performed in accordance with the ethical standards, with ethical approval obtained for the use of drug-free human blood from the Royal Brisbane \& Women's Hospital Human Research Ethics Committee HREC/15/QRBW/249.

Conflict of interest The authors declare that they have no conflict of interest. 


\section{References}

1. World Health Organisation. Global priority list of antibioticresistant bacteria to guide research, discovery, and development of new antibiotics. 2017. https://www.who.int/medicines/ publications/global-priority-list-antibiotic-resistant-bacteria/en/. Accessed 18 June 2019.

2. U.S. Food and Drug Administration. FDA approves new antibacterial drug. 2017.

3. Eurpean Medicines Agency (EMA). Zerbaxa: EPAR - Product Information. 2018.

4. Sakoulas G. Meropenem/vaborbactam approved in U.S. for Complicated Urinary Tract Infection. NEJM Group; 2018. https:// www.jwatch.org/na45133/2017/10/18/meropenem-vaborbactamapproved-us-complicated-urinary. Accessed 12 Sept 2019.

5. Alexander EL, Loutit J, Tumbarello M, Wunderink R, Felton T, Daikos G, et al. Carbapenem-resistant Enterobacteriaceae infections: results from a retrospective series and implications for the design of prospective clinical trials. Open Forum Infect Dis. 2017;4(2). https://doi.org/10.1093/ofid/ofx063.

6. Sime FB, Pandey S, Karamujic N, Parker S, Alexander E, Loutit J, et al. Ex vivo characterization of effects of renal replacement therapy modalities and settings on pharmacokinetics of meropenem and vaborbactam. Antimicrob Agents Chemother. 2018;62(10). https:// doi.org/10.1128/aac.01306-18.

7. Roberts DM, Roberts JA, Roberts MS, Liu X, Nair P, Cole L, et al. Variability of antibiotic concentrations in critically ill patients receiving continuous renal replacement therapy: a multicentre pharmacokinetic study. Crit Care Med. 2012;40(5):1523-8. https://doi. org/10.1097/CCM.0b013e318241e553.

8. Seyler L, Cotton F, Taccone FS, De Backer D, Macours P, Vincent $\mathrm{JL}$, et al. Recommended beta-lactam regimens are inadequate in septic patients treated with continuous renal replacement therapy. Crit Care. 2011;15(3). https://doi.org/10.1186/cc10257.

9. Rubino CM, Bhavnani SM, Loutit JS, Morgan EE, White D, Dudley MN, et al. Phase 1 study of the safety, tolerability, and pharmacokinetics of vaborbactam and meropenem alone and in combination following single and multiple doses in healthy adult subjects. Antimicrob Agents Chemother. 2018;62(4):12. https:// doi.org/10.1128/aac.02228-17.

10. Abdulla A, Bahmany S, Wijma RA, van der Nagel BCH, Koch BCP. Simultaneous determination of nine beta-lactam antibiotics in human plasma by an ultrafast hydrophilic-interaction chromatography-tandem mass spectrometry. J Chromatogr B Analyt Technol Biomed Life Sci. 2017;1060:138-43. https://doi.org/10.1016/j. jchromb.2017.06.014.

11. Barco S, Bandettini R, Maffia A, Tripodi G, Castagnola E, Cangemi G. Quantification of piperacillin, tazobactam, meropenem, ceftazidime, and linezolid in human plasma by liquid chromatography/ tandem mass spectrometry. J Chemother. 2015;27(6):343-7. https://doi.org/10.1179/1973947814y.0000000209.

12. Briscoe SE, McWhinney BC, Lipman J, Roberts JA, Ungerer JPJ. A method for determining the free (unbound) concentration of ten beta-lactam antibiotics in human plasma using high performance liquid chromatography with ultraviolet detection. J Chromatogr B Analyt Technol Biomed Life Sci. 2012;907:178-84. https://doi.org/ 10.1016/j.jchromb.2012.09.016.

13. Carlier M, Stove V, De Waele JJ, Verstraete AG. Ultrafast quantification of beta-lactam antibiotics in human plasma using UPLC-MS/ MS. J Chromatogr B Analyt Technol Biomed Life Sci. 2015;978: 89-94. https://doi.org/10.1016/j.jchromb.2014.11.034.

14. Carlier M, Stove V, Roberts JA, Van de Velde E, De Waele JJ, Verstraete AG. Quantification of seven beta-lactam antibiotics and two beta-lactamase inhibitors in human plasma using a validated
UPLC-MS/MS method. Int J Antimicrob Agents. 2012;40(5):41622. https://doi.org/10.1016/j.ijantimicag.2012.06.022.

15. Casals G, Hernandez C, Hidalgo S, Morales B, Lopez-Pua Y, Castro P, et al. Development and validation of a UHPLC diode array detector method for meropenem quantification in human plasma. Clin Biochem. 2014;47(16-17):223-7. https://doi.org/10. 1016/j.clinbiochem.2014.08.002.

16. Chang P, Dai LL, Zhang DJ, Wang BJ, Guo RC. Determination of meropenem in human plasma by HPLC: validation and its application to pharmacokinetic study. Lat Am J Pharm. 2014;33(5):870-4.

17. Colin P, De Bock L, T'Jollyn H, Boussery K, Van Bocxlaer J. Development and validation of a fast and uniform approach to quantify beta-lactam antibiotics in human plasma by solid phase extraction-liquid chromatography-electrospray-tandem mass spectrometry. Talanta. 2013;103:285-93. https://doi.org/10.1016/j. talanta.2012.10.046.

18. D'Cunha R, Bach T, Young BA, Li PZ, Nalbant D, Zhang J, et al. Quantification of cefepime, meropenem, piperacillin, and tazobactam in human plasma using a sensitive and robust liquid chromatography-tandem mass spectrometry method, part 1: assay development and validation. Antimicrob Agents Chemother. 2018;62(9):15. https://doi.org/10.1128/aac.00859-18.

19. Ferrari D, Ripa M, Premaschi S, Banfi G, Castagna A, Locatelli M. LC-MS/MS method for simultaneous determination of linezolid, meropenem, piperacillin and teicoplanin in human plasma samples. J Pharm Biomed Anal. 2019;169:11-8. https://oi.org/10.1016/j. jpba.2019.02.037.

20. Ferrone V, Cotellese R, Di Marco L, Bacchi S, Carlucci M, Cichella A, et al. Meropenem, levofloxacin and linezolid in human plasma of critical care patients: a fast semi-automated micro-extraction by packed sorbent UHPLC-PDA method for their simultaneous determination. J Pharm Biomed Anal. 2017;140:266-73. https://doi.org/ 10.1016/j.jpba.2017.03.035.

21. Martens-Lobenhoffer J, Bode-Boger SM. Quantification of meropenem in human plasma by HILIC - tandem mass spectrometry. J Chromatogr B Analyt Technol Biomed Life Sci. 2017;1046: 13-7. https://doi.org/10.1016/j.jchromb.2017.01.016.

22. Sime FB, Roberts MS, Roberts JA, Robertson TA. Simultaneous determination of seven beta-lactam antibiotics in human plasma for therapeutic drug monitoring and pharmacokinetic studies. J Chromatogr B Analyt Technol Biomed Life Sci. 2014;960:13444. https://doi.org/10.1016/j.jchromb.2014.04.029.

23. Wolff F, Deprez G, Seyler L, Taccone F, Hites M, Gulbis B, et al. Rapid quantification of six beta-lactams to optimize dosage regimens in severely septic patients. Talanta. 2013;103:153-60. https:// doi.org/10.1016/j.talanta.2012.10.024.

24. Paal M, Zoller M, Schuster C, Vogeser M, Schutze G. Simultaneous quantification of cefepime, meropenem, ciprofloxacin, moxifloxacin, linezolid and piperacillin in human serum using an isotope-dilution HPLC-MS/MS method. J Pharm Biomed Anal. 2018;152:102-10. https://doi.org/10.1016/j.jpba.2018.01.031.

25. Rigo-Bonnin R, Juvany-Roig R, Leiva-Badosa E, Sabater-Riera J, Perez-Fernandez XL, Cardenas-Campos P, et al. Measurement of meropenem concentration in different human biological fluids by ultra-performance liquid chromatography-tandem mass spectrometry. Anal Bioanal Chem. 2014;406(20):4997-5007. https://doi.org/ 10.1007/s00216-014-7910-9.

26. Roth T, Fiedler S, Mihai S, Parsch H. Determination of meropenem levels in human serum by high-performance liquid chromatography with ultraviolet detection. Biomed Chromatogr. 2017;31(5). https:// doi.org/10.1002/bmc.3880.

27. Zander J, Maier B, Suhr A, Zoller M, Frey L, Teupser D, et al. Quantification of piperacillin, tazobactam, cefepime, meropenem, ciprofloxacin and linezolid in serum using an isotope dilution UHPLC-MS/MS method with semi-automated sample preparation. 
Clin Chem Lab Med. 2015;53(5):781-91. https://doi.org/10.1515/ cclm-2014-0746.

28. Ferrone V, Cotellese R, Cichella A, Raimondi P, Carlucci M, Palumbo P, et al. Meropenem and ciprofloxacin in complicated gastric surgery for cancer patients: a simple SPE-UHPLC-PDA method for their determination in human plasma. Biomed Chromatogr. 2019;33(3):8. https://doi.org/10.1002/bmc.4450.

29. Hakobyan L, Tolos JP, Moliner-Martinez Y, Molins-Legua C, Ramos JR, Gordon M, et al. Determination of meropenem in endotracheal tubes by in-tube solid phase microextraction coupled to capillary liquid chromatography with diode array detection. J Pharm Biomed Anal. 2018;151:170-7. https://doi.org/10.1016/j. jpba.2018.01.006.

30. Lefeuvre S, Bois-Maublanc J, Hocqueloux L, Bret L, Francia T, Eleout-Da Violante C, et al. A simple ultra-high-performance liquid chromatography-high resolution mass spectrometry assay for the simultaneous quantification of 15 antibiotics in plasma. J Chromatogr B Analyt Technol Biomed Life Sci. 2017;1065:50-8. https://doi.org/10.1016/j.jchromb.2017.09.014.

31. Food US, Administration D. Bioanalytical method validation: guidance for industry. MD: Rockville; 2018.

32. European Medicines Agency (EMA). Guideline on bioanalytical method validation. London, UK; 2011.

33. Matuszewski BK, Constanzer ML, Chavez-Eng CM. Strategies for the assessment of matrix effect in quantitative bioanlaytical methods based on HPLC-MS/MS. Anal Chem. 2003;75(13): 3019-30.
34. Sun C, Wu J, Pan Y. Characterization of novel hydrolysis products of carbapenems by electrospray ionization mass spectrometry. Rapid Commun Mass Spectrom. 2009;23:3205-12. https://doi. org/10.1002/rcm.4240.

35. Lowes S, Jersey J, Shoup R, Garofolo F, Savoie N, Mortz E, et al. Recommendations on: internal standard criteria, stability, incurred sample reanalysis and recent 483 s by the Global CRO Council for Bioanalysis. Bioanalysis. 2011;3(12):1323-32. https://doi.org/10. 4155/bio.11.135.

36. Minichmayr IK, Roberts JA, Frey OR, Roehr AC, Kloft C, Brinkmann A. Development of a dosing nomogram for continuous-infusion meropenem in critically ill patients based on a validated population pharmacokinetic model. J Antimicrob Chemother. 2018;73(5):1330-9. https://doi.org/10.1093/jac/ dkx526.

37. Kufel WD, Eranki AP, Paolino KM, Call A, Miller CD, Mogle BT. In vivo pharmacokinetic analysis of meropenem/vaborbactam during continuous venovenous haemodialysis. J Antimicrob Chemother. 2019;74(7):2117-8. https://doi.org/10.1093/jac/ dkz103.

38. Sjovall F, Alobaid AS, Wallis SC, Perner A, Lipman J, Roberts JA. Maximally effective dosing regimens of meropenem in patients with septic shock. J Antimicrob Chemother. 2018;73(1):191-8. https://oi.org/10.1093/jac/dkx330.

Publisher's note Springer Nature remains neutral with regard to jurisdictional claims in published maps and institutional affiliations. 